\title{
WEDGE-TAILED SHEARWATERS, PUFFINUS PACIFICUS, AND DEVELOPMENT ON HERON ISLAND, GREAT BARRIER REEF, AUSTRALIA
}

\author{
by Johanna Rosier and Pam Dyer
}

(with three text-figures)

\begin{abstract}
Rosier, J. \& Dyer, P. 2008 (31:x): Wedge-tailed Shearwaters, Puffinus pacificus, and development on Heron Island, Great Barrier Reef, Australia. Papers and Proceedings of the Royal Society of Tasmania 1 42(1): 99-104. https://doi.org/10.26749/rstpp.142.1.99 ISSN 0080-4703. Faculty of Arts and Social Sciences, University of the Sunshine Coast, Maroochydore DC, Queensland 45 58, Australia.(JR*, PD).*Author for correspondence. Email: Jrosier@usc.edu.au
\end{abstract}

\begin{abstract}
The Wedge-tailed Shearwater, Puffinus pacificus, colony on Heron Island, Great Barrier Reef, Australia, has been the subject of a long-term study since 1984 to monitor the effects of development. During this time, there has been considerable development in the tourist resort, university research station and national park ranger quarters. Several methods have been used to record and analyse the effects of development. Prior to the development of specialised burrow-viewing equipment, Wedge-tailed Shearwater population estimates had been based on indirect methods such as footprints and cleared burrow entrances. Investigation of actual burrow contents, relayed electronically from a camera inserted into burrows showed that all previous population estimates needed revision, even halving earlier populations estimates. We also used a photographic record and surveys to record the changes to island habitats over time. The Ultimate Environmental Threshold (UET) technique was used to estimate the effects of development on several environmental factors. Traditional breeding areas have been lost to the shearwater population through construction of buildings, paving of areas, blocking of flight paths and compaction of tracks. However, the species appears to have compensated despite significant modification to the island's natural habitats. Nesting behaviour has been altered in disturbed areas of the island and egg-hatching rates have been lowered. Because the life span of a shearwater could be up to 30 years, more long-term research is needed to analyse the true effects of development.
\end{abstract}

Key Words: Heron Island, Great Barrier Reef, Wedge-tailed Shearwater, Puffinus pacificus, tourist resort, university research station, National Park, tourism, seabirds.

\section{INTRODUCTION}

The effects of tourism development on a seabird-breeding island on the Great Barrier Reef (GBR) in Australia may seem far removed from the interests of researchers concerned with the temporal and spatial effects of urbanisation on birds. However, we will demonstrate how many of the issues facing urban bird species (habitat fragmentation, edge effects, population stability, nesting success and the effects of human disturbance) also are present on Heron Island, despite its remoteness. Because the western half of the island is densely developed, the habitat of the Wedge-tailed Shearwater, Puffinus pacificus (J.F. Gmelin, 1789), can be likened to fringe areas of urbanised centres.

The Great Barrier Reef Marine Park Authority (GBRMPA) and the Queensland Parks and Wildlife Service (QPWS) are jointly responsible for managing the effects of human use of marine areas, especially the reefs. The island national parks are managed solely by the QPWS. The World Heritage-listed Great Barrier Reef Marine Park is managed on a multiple-use basis to achieve sustainable development. The GBR World Heritage Area (WHA) has a different boundary to the GBR Marine Park with different management requirements. For instance, all the islands are in the World Heritage area but not in the GBR Marine Park. They are part of Queensland's state lands and are part of Queensland. The main human activities are tourism, recreation, fishing and research. The islands provide bases from which most reef activities are carried out. Access points to the islands and the reef tourism sites are on the mainland (e.g., Cairns, Townsville, Mackay, Airlie Beach-Shute Harbour), with a few resorts mainly on continental islands.

Heron Island is one of the few resorts actually located on the Great Barrier Reef and is accessed from Gladstone. The island is a sand "cay" within the Capricorn/Mackay
Section of the Great Barrier Reef Marine Park (GBRMP) (fig. 1) with a vegetated area of 13.5 ha (Hill \& Barnes 1989, Dyer et al. 1995). QPWS measures note the area of the island as being 19 ha in total (Davie \& Winter 1988) and that it is divided into three areas: the national park (QPWS - 12.3 ha), Heron Island Resort (HIR - Qld lease of $4.7 \mathrm{ha}$ ) and the Heron Island Research Station (HIRS $2.3 \mathrm{ha}$ ), on land which has been leased from the QPWS by the University of Queensland for many years with the latest lease commencing in October 2002. An esplanade forms the remaining 2.3 ha of the national park. Approximately $75 \%$ of the land has national park status.

The resort lease is autonomous in that there are no conditions about development limitations on the lease documents. The lease agreement for the research station, which is part of the national park, stipulates limitations on permitted activities - so that they remain appropriate to the national park status of the area. When the research station's lease was renewed in 2002, additional conditions were also placed on its activities. Leaseholders have agreed to conform to the Heron Island Management Guidelines (Hunnam 1983, Davie \& Winter 1988), which set limits on development, landscaping and activities by all parties on the island. Development of the island is also subject to the other guidelines (QPWS 2000).

The most striking feature of the cay's vegetation is the central core of Pisonia grandis R.Br. forest (Hill \& Rosier 1989, Dyer \& Hill 1992), which is surrounded by a fringe of wind/salt-tolerant vegetation consisting of Argusia, Casuarina and Pandanus spp, as well as stunted $P$. grandis. Another feature of the northern fringe area is the dense ground cover of grasses, many of which are introduced species.

The main ecological values of the marine park depend not only on the importance of the islands as breeding sites for turtles and a number of seabird species, but also on their 

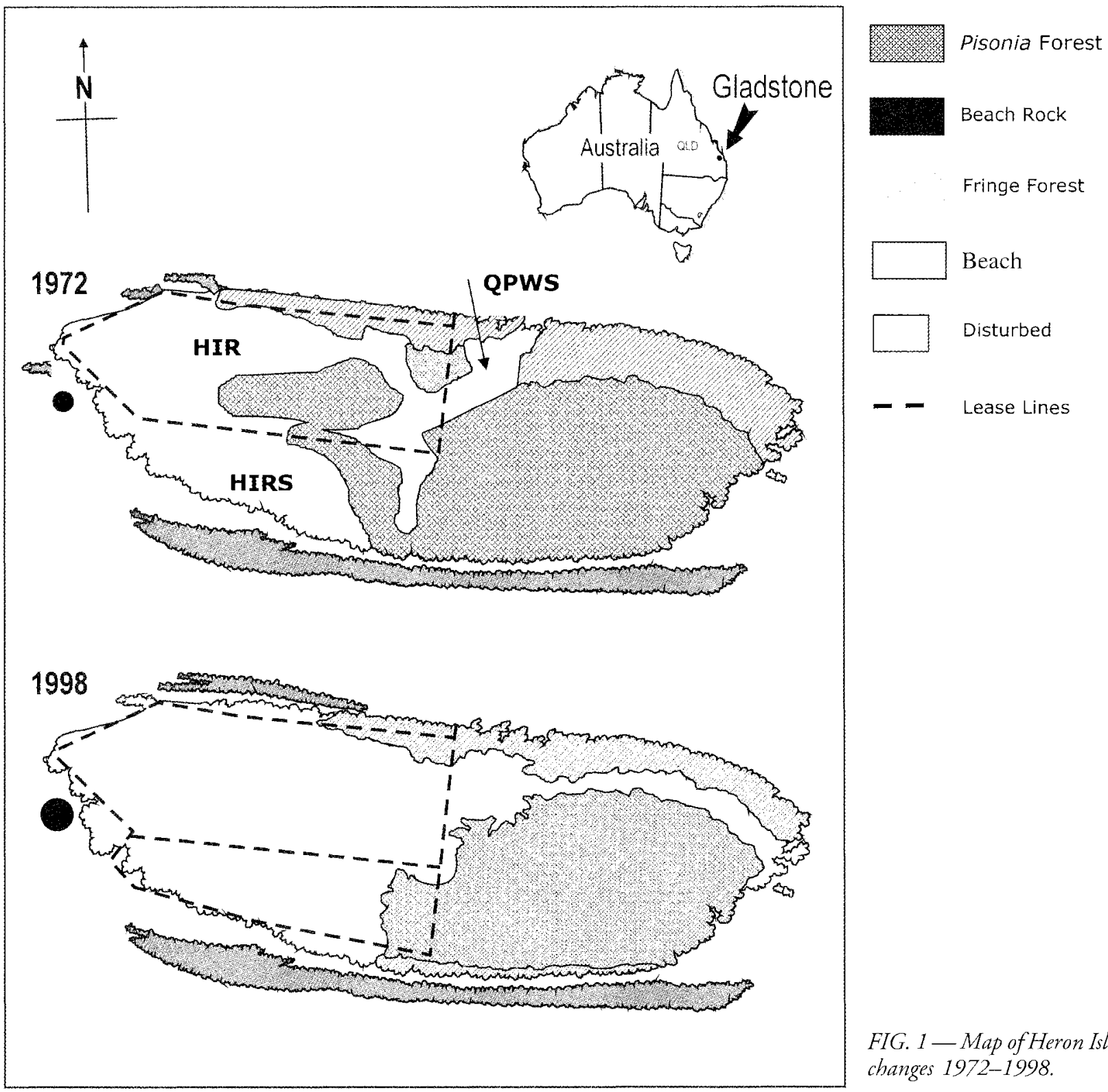

FIG. 1-Map of Heron Island changes 1972-1998.

usefulness for educating people about the natural values of the island habitats and surrounding reef and tourism opportunities. In the 1800 s and early 1900s, wildlife resources (e.g., nesting turtles, mainly Chelonia mydas (Linnaeus, 1758)) or wildlife-related resources (e.g., guano) have formed the basis of exploitative industries (QPWS 2000). All these types of activities involve manipulation of the resource base, albeit with differing degrees of impact. However, even relatively benign development, such as the establishment of a scientific research station or ranger station, requires that decisions about the location of facilities and activities be based on a spatial analysis of environmental variables to achieve the sustainable use of resources and avoid potential, irreversible impacts on the environment.

The human population of the island is difficult to assess, particularly in the resort area. HIR regards this information as commercially sensitive. Ferrier (1984) noted that the island population varied between 400 and 600 people (based on an annual turnover rate for visitors in the vicinity of 10000 guests per year). This figure included tourist resort guests and staff, HIRS research and maintenance personnel and QPWS officers stationed in the National Park Headquarters.
By 1986 the resort recorded 49000 visitors yearly, and by March 1987, the resort was already catering for 1200 guests per week or 60000 visitors on an annual basis. The research station accommodates up to 84 researchers and students, and the QPWS base houses up to 11 people mainly during turtle nesting season. Increasing demands for development space in each leased area is impacting on the available space for Wedge-tailed Shearwater breeding. The island management committee and QPWS have no formal framework for monitoring the impacts of development on any part of the environment. Current monitoring of development is focused on managing the national park area of the island rather than the leased areas. Following the fire in 2007, the research station is establishing a more comprehensive database to record all research sites on the island.

\section{METHOD}

In view of the fact that shearwater nesting areas (and those of other species) need to be protected (Kozlowski 1985), the Ultimate Environmental Threshold (UET) method 
was applied to Heron Island to determine areas from which development and activities should be excluded, if development was happening for the first time (Rosier $e t a l$. 1986, Kozlowski et al. 1988, Hill \& Rosier 1989). UET evaluates the quality of environmental elements relative to the consequences of development and use. To define UET thresholds to development, each of the relevant elements on Heron Island (geomorphological structure, vegetation, seabirds and turtles) was assessed according to its ecological significance or rarity, resistance or ability to cope with human disturbance, and transformation or degree of change "by humans" from its pristine state. The information gained facilitated assessment of the spatial compatibility between current development on Heron Island (across all lease areas and the national park) and the Wedge-tailed Shearwater breeding areas. The results were also used to retrospectively critique decisions about development. A series of planning inspections and photographs taken over 14 years provide a quantifiable record of development over time.

We also monitored breeding populations of Wedge-tailed Shearwaters which are monogamous pelagic seabirds. On Heron Island, they nest in burrows located in areas likely to be impacted by development (i.e., in vegetated areas above the Mean High Tide mark beyond turtle nesting areas). We visited Heron Island in both August and November/ December each year from 1984-1987, in December 1988-1991, and in January 1998 and 1999.

The Heron Island Wedge-tailed Shearwater nesting population has been surveyed regularly since 1983. Prior to the development of specialised burrow-viewing equipment (Dyer \& Hill 1991, Dyer \& Aldworth 1998), population estimates were based on indirect methods such as footprints, cleared burrow entrances, and fresh guano. This was inefficient as non-breeding birds utilise empty burrows leaving the impression that the burrow supports breeding activities. Conversely burrows that have entrances covered by leaves, seemingly devoid of nesting activity, are just as likely to be occupied by breeding birds (Dyer 1990, 1991).
Thus, population estimates based on burrow counts needed to be adjusted according to breeding activities occurring within the burrows.

Shearwater population censuses (1985-1990 and 1999) were derived by collecting data concerning the number of burrows, burrow status and different habitat types (e.g., Disturbed, Fringe areas, $P$. grandis forest). Figure 1 shows the habitat changes since mapping began in 1972. Data were collected for contiguous quadrats, forming systematically spaced transects that traversed the island in a north--south direction (Dyer \& Hill 1990, Dyer 1992, Hill et al. 1995, 1996, Dyer et al. 2005). Following the introduction of the burrowscope, Carter et al. (1996a, b) and Carter (1997) investigated rates of breeding success at the hatching and fledgling stages for shearwater chicks for the $1993 / 4$ breeding season. The study focused on analysing the environmental variables such as soil moisture, nest density and soil strength. Selected burrows were monitored four times during the nesting season, with timing coinciding with egg-laying, hatching, fledging and departure of fledglings. Linear Structural Relations (LISREL) models were applied to one-off habitat measurements to determine the most likely influences of various variables on breeding success.

In addition, Dyer et al. $(1995,2005)$ attempted to rationalise all previously published population estimates for Wedge-tailed Shearwaters in the Capricorn Group. Most population estimates had been established by doubling burrow counts, assuming a breeding pair for each burrow (fig. 2). Where available, data other than those provided by the authors were re-worked to standardise earlier population estimates with those of Dyer, Hill, Rosier and Carter (fig. 2). The outcome, though relatively crude, was considered an improvement over data taken at face value for comparative purposes. However, because incubation rates of about $50 \%$ were not significantly different between two seasons, it was proposed that all previous population estimates based on burrow counts should be at least halved (Dyer 1992).

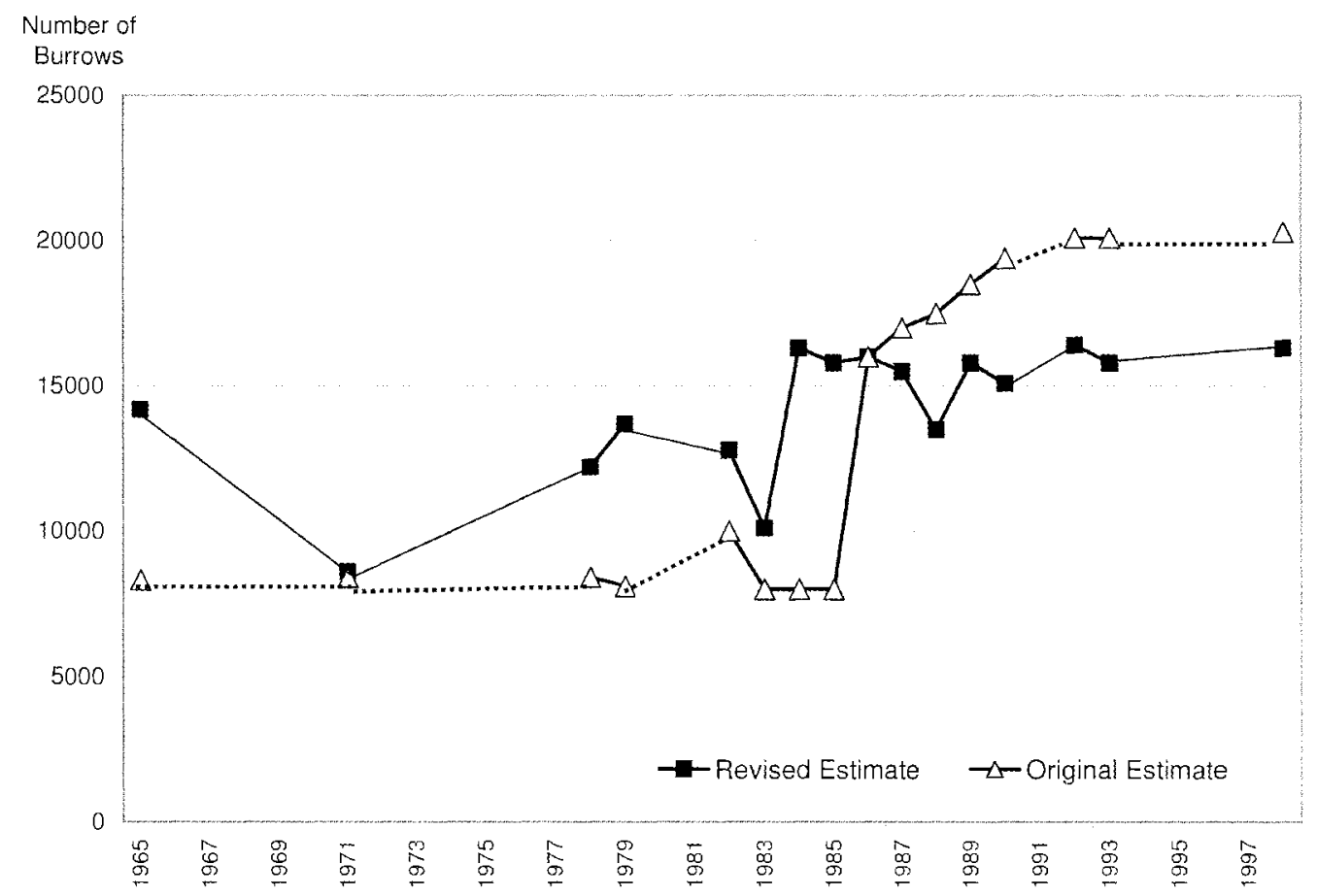

FIG. 2 - Rationalisation of Wedge-tailed Shearwater burrow estimates. 


\section{RESULTS}

The UET analysis determined that before 1988, only the research station buildings had a significant effect on potential nesting areas for shearwaters. The resort had already been constructed and the habitat area virtually lost (Hill \& Rosier 1989). In addition, the habitat available to birds on the northern side of the island is less favourable because of the dry, sandy soil. Neil \& Dyer (1992:37) found that "burrowing density tends to increase into the mid part of the soil strength range ... favouring sites where the soil is loose enough to burrow easily, but not so loose as too collapse" (the dry sandy soils in the resort area). Subsequent development (sewerage treatment station and new road bewween the resort and the QNPWS station) has compromised ecologically sensitive areas in the centre of the island, characterised by closed P. grandis forest. By 1998, only 30\% of the Pisonia forest remained and only $11 \%$ of the fringe area remained relatively undisturbed. Figure 3 shows the changes which have occurred in habitat areas over the years that management plans were prepared. The UET analysis assumed that prior to permanent human occupation in the $1960 \mathrm{~s}, P$. grandis forest was the preferred habitat type for shearwater breeding areas. However, subsequent monitoring on Heron Island demonstrates that shearwaters nest in both the Pisonia forest and fringe areas bordering the forest (Rosier et al. 1986, Kozlowski et al. 1988).

Based on the number of shearwater burrows on Heron Island, the Wedge-tailed Shearwater population had fluctuated around a mean of about 15000 burrows for the 35 years to 1995 . The results of the annual surveys (1985-1989) showed no significant trends in the burrow estimates for the entire island or for either the western (disturbed) or eastern (least disturbed) sides of the island. By December 1989, there was a significant difference in overall burrow numbers between the eastern and western sides $\left[\mathrm{t}_{18}=2.1, \mathrm{P}<0.05\right.$ (independent two-tailed test) $]$ of the island, but this was no longer evident in December 1990, suggesting habituation by shearwaters (Hill et al. 1995). A preliminary 1999 census resulting in about 16500 burrows overall is within normal parameters but significantly fewer burrows were found between non-developed and developed areas (5:3), that is between eastern and western sides of the island $\left[\mathrm{t}_{12}=2.2, \mathrm{P}<0.05\right.$ (independent two-tailed test)]. It appears that birds have now compensated for the loss of habitat in developed areas by nesting at higher densities in the national park. Only when current research is complete will it be clear whether this pattern of shearwater nesting has now become more permanent or whether this is a temporary aberration similar to the findings for December 1989.

Burrow occupancy rates between December 1989 (43\%) and December 1990 (49\%) were not significantly different between seasons for the island as a whole $\left(\chi^{2}=1.75, \mathrm{df}=1\right.$, $\mathrm{P}>0.1)$, or for the individual habitats types $\left(\chi^{2}=2.6, \mathrm{df}=\right.$ $4, \mathrm{P}>0.6)$. Although the buildings category of nesting area supported occupancy rates of $52 \%$ in December 1989 and $44 \%$ in December $1990\left(\chi^{2}=0.86, \mathrm{df}=1, \mathrm{P}>0.3\right.$ ) (Dyer 1992, Hill et al. 1995), the difference was not significant. The developed habitat had low burrow densities ranging from 0.015 to 0.031 per $\mathrm{m}^{2}$ between 1985 and 1990 . The P. grandis forest and fringe habitats, together covering about $50 \%$ of the island for the 1980 s studies provide the main nesting habitats for Wedge-tailed Shearwaters. These support between $60 \%$ and $78 \%$ of the burrows depending on the year (Hill et al. 1995). This habitat has been reduced so much that it only covered approximately $41 \%$ of the island in January 1998 (figs 1, 3) and supported about 84\% of total burrows.

Hill et al. (1996) show that the disturbed habitat on Heron Island has significantly lower hatching success $(56.76 \%)$ compared with up to $80 \%$ hatching success in the fringe and Pisonia forest $\left(\chi^{2}=13.186, \mathrm{df}=3, \mathrm{P}<0.005\right)$. Substrate soil moisture and nesting density were found to be the major factors affecting breeding success of shearwaters on Heron Island (Carter 1997). For example, low substrate soil moisture is needed while nests are being excavated, but higher soil moisture is needed to ensure successful hatching of fledglings. However, further research is needed before we can show whether it is moisture elements that cause low breeding success in the disturbed area.

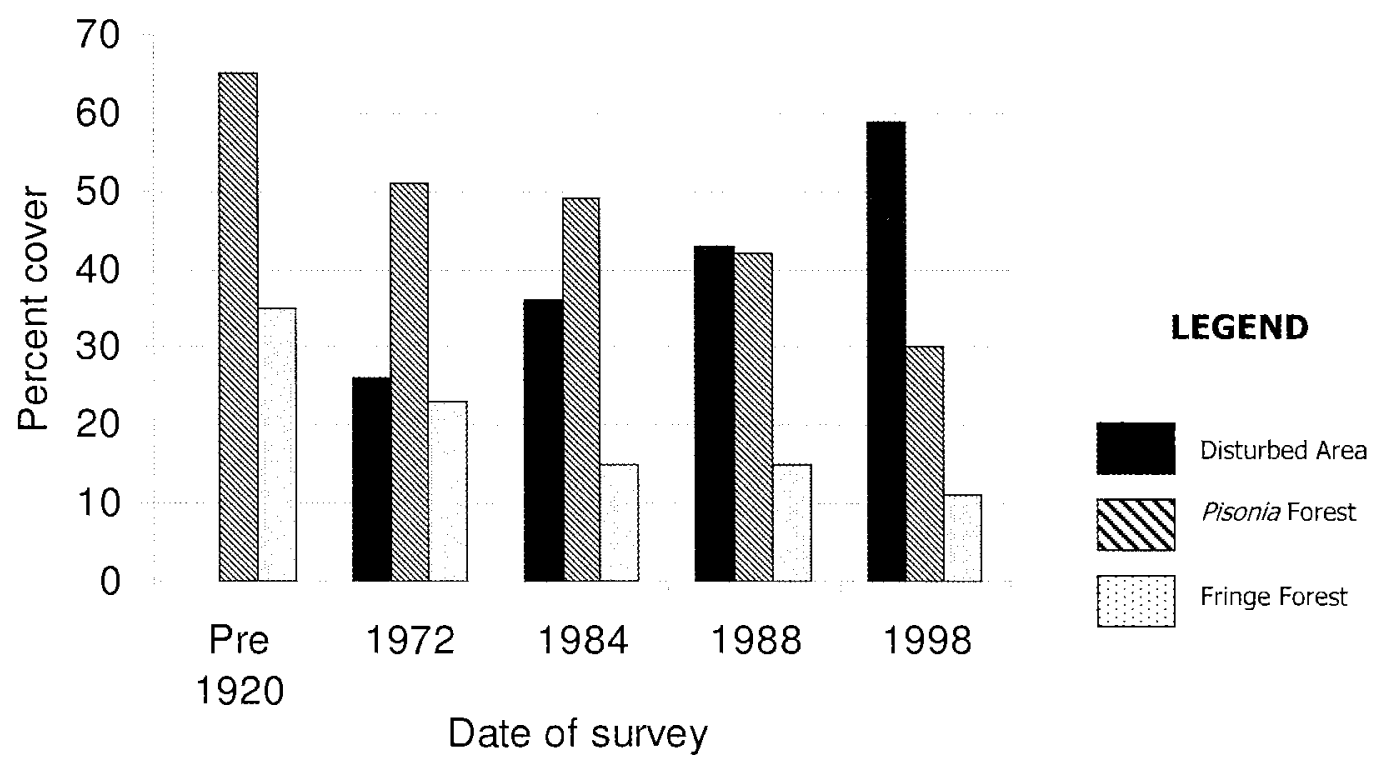

FIG.3 - Changes to Heron Island habitat type with increased development. 


\section{DISCUSSION}

\section{Management implications}

Heron Island has undergone substantial change, especially since the $1960 \mathrm{~s}$ when the resort was established. Most change has been unplanned in terms of anticipating and understanding the effects of development on shearwater nesting areas. The cumulative spatial impacts of small incremental building projects would not have been tolerated had the total development been proposed as a single development project. None of the planning mechanisms to limit development or activities (esplanade and buffer zoning, total human population limits, height and extent of building limits, restriction of vehicular access or prohibition of activities) has been implemented consistently over time. The results of this research highlight the effects of increased development on shearwater nesting density, breeding success, inter-island movement of seabirds and vulnerability of ground-nesting seabirds.

Shearwater nesting densities on Heron Island are consistently lower compared with corresponding areas on North West and Masthead islands (Hulsman 1983). The problem is determining the degree to which human disturbance has caused lower nesting densities and the subsequent effect of those lower nesting densities on breeding success. Construction of structures, dumping of building products in the national park area of Pisonia forest and the increased compaction of areas such as roads, paths and recreation areas preclude nesting by shearwaters. Buildings now block half of the shearwater flight paths mapped in 1983. There also has been little research into the patterns of nesting, an aspect that appears to be important to birds nesting synchronously (Nelson 1980).

Breeding success rates of Wedge-tailed Shearwaters on Heron Island are still not known (Carter et al. 1996b), although shearwaters seem to be relatively resilient. They appear to have responded to exclusion from earlier sites by burrowing in higher densities or moving to other parts of the island. It cannot, however, be assumed that altered nesting patterns are not in themselves detrimental to breeding success rates. Therefore, after 14 years of research it is still difficult to determine conclusively that development will impact negatively on the shearwater population over the long term. Research about breeding success rates over time are needed so that the real effect of human impacts can be determined. The opportunity to monitor occupancy rates has not arisen since Carter's 1993/4 study.

The Capricorn Group of islands has several shearwater breeding islands in addition to Heron Island. Management plans should include analysis of the relationship between colonies and indicators for monitoring human impacts on seabird-nesting areas across the island group. Ideally, protection of seabird colonies requires critical areas be set aside as sanctuaries; access is controlled; information about the birds and restrictions on access is readily available; and the effects of human disturbance are understood (Segnestam 1975, Anderson \& Keith 1980, Feare 1984, WBM Oceanics \& Claridge 1997). To achieve this, the following questions need to be answered.

What is the acceptable area and level of development in the long term?

What constraints must be imposed on development and people's activities to ensure that natural areas are managed effectively to ensure that reproductive success of seabirds is not threatened?

One of the major research problems in the Capricorn Group of islands is the lack of knowledge about seabird movement between islands. Therefore, any policy that relies on sacrificing one island for development (QPWS 1980) may have detrimental long-term effects on the island group. When researching the characteristics of the colonies, few scientists have commented on the status of other colonies throughout the world. This also may affect decisions concerning development on islands of seemingly minor importance in the region. The data sets required to provide quantitative assessments of the significance of the colonies and the effects of human disturbance are extensive and involve in-depth understanding of total ecosystems (e.g., worldwide distribution of a species) as well as their component parts (e.g., local distribution and ecology of a species). As Hulsman (1983) points out, it may take up to ten years to gather relevant data and this is conditional on a decision to do so by management authorities.

The effects of human activities on ground-nesting seabirds are particularly difficult to evaluate (Anderson \& Keith 1980). Resistance of Wedge-tailed Shearwaters may be gauged superficially only due to a lack of research into this aspect of their ecology. Nelson (1980) reports that disturbed sites are less attractive as nesting areas although this does not appear to be a universal phenomenon (Hill \& Barnes 1989, Dyer \& Hill 1990, Carter 1997). Since Shearwaters lay only one egg per season, any damage to the nesting burrow during the nesting season will affect success. The physical layout of burrows is such that severe damage occurs if humans enter an area with high burrow densities. This applies to both breeding and non-breeding seasons (Nelson 1980).

There are two major conclusions from our ongoing study. First, there has been a major reduction of shearwater breeding habitats on Heron Island since 1972 when mapping of habitat and development first occurred. Development decisions have been made on an ad-hoc basis with no overall strategy guiding tourist or research station development. All plans and monitoring of development have not taken into account the long-term protection of ecological values and the natural characteristics that attract and educate tourists, especially in relation to the ground-nesting shearwaters.

Second, current results demonstrate that, despite the foreboding/concerns of various researchers (Hulsman 1983, Hill \& Rosier 1989), the effects of development on the shearwater population have to date been minor. Alternatively, it may be that potential adverse effects implied by the lower hatching rates in the developed areas are not yet apparent. Despite the significant modification of Heron Island's natural environment and despite human activities on nearby uninhabited islands, Wedge-tailed Shearwaters in the Capricorn Group of islands appear to have acclimated to the presence of humans. The degree of impact over the long term will be difficult to gauge without understanding the optimum levels of breeding populations, research that requires many years of work. Shearwaters do not return to breeding colonies for five years after fledging and the life span of shearwaters could be up to 30 years. All these factors need to be factored in to modelling of human impacts. 


\section{REFERENCES}

Anderson, D.W. \& Keith, J.O. 1980: The human influence on seabird nesting success: Conservation implications. Biological Conservation 18: 65-80.

Carter, J. 1997: Nest-site selection and breeding success of Wedgetailed Shearwaters (P'uffinus pacificus) at Heron Island. Australian Geographical Studies 35: 153-167.

Carter, J.L., Dyer, P.K. \& Hill, G.J.E. 1996a: Body dimensions of Wedge-tailed Shearwater (Puffinus pacificus) fledglings ar Heron Island, Great Barrier Reef, and the importance of timing of breeding. Corella 20: 141-143.

Carter, J.L., Hill, G.J.E. \& Dyer, P.K. 1996b: Breeding cycle of Wedge-tailed Shearwaters (Puffinus pacificus) at Heron Island, Great Barrier Reef. Emu 96: 195-198.

Davie, J.D.S. \& Winter, E.M. 1988: Heron Island Management Plan: Guidelines, Designs and standards for the integrated development of Heron Island Resort, Research Station and National Park. Queensland National Parks and Wildlife Service, Gladstone: $43 \mathrm{pp}$.

Dyer, P.K. 1990: Observation of burrow covering activity by a Wedge-tailed Shearwater. Corella 14: 122-123.

Dyer, P.K. 1991: Covered entrances of Wedge-tailed Shearwater burrows. Corella 15: 103-107.

Dyer, P.K. 1992: Wedge-tailed Shearwater nesting patterns: a spatial and ecological perspective, Capricorn Group, Great Barrier Reef. Unpublished PhD thesis, The University of Queensland.

Dyer, P.K. \& Aldworth, K. 1998: The "burrowscope": modifications to burrow viewing equipment. Emu $\mathbf{9 8}$ $143-146$.

Dyer, P.K. \& Hill, G.J.E. 1990: Nearest neighbor analysis and Wedge-tailed Shearwater burrow patterns on Heron and Masthead islands, Great Barrier Reef. Australian Geographical Studies 28: 51-61.

Dyer, P. \& Hill, G.J.E. 1991: A solution to the problem of determining the occupancy status of Wedge-tailed Shearwater (Puffinus pacificus) burrows. Emu 91: 20-25.

Dyer, P.K. \& Hill, G.J.E. 1992: Active breeding burrows of the Wedge-tailed Shearwater in the Capricorn Group, GBR. Ети 92: 147-151.

Dyer, P.K., Hill, G.J.E. \& Barnes, A. 1995: Three decades of burrow estimates for Wedge-tailed Shearwaters on the Capricorn Group of islands - an attempted rationalisation. Ети 95: 272-279.

Dyer, P.K., O'Neill, P.O. \& Hulsman, K. 2005: Breeding numbers and population trends of Wedge-tailed Shearwater (Puffinus pacificus) and Black Noddy (Anous minitus) in the Capricornia Cays, southern Great Barrier Reef. Emu 105: 249-257.

Feare, C.J. 1984: Seabirds as a resource: use and management. In Stoddart, D. R. (ed.): Biogeography and Ecology of the Seychelles Islands. Dr W Junk Publishers, The Hague: 593-605.
Ferrier, A.I. 1984: Major coastal and tourism developments. Queensland Planner 24: 18-23.

Hill, G.J.E. \& Barnes, A. 1989: Census and Distribution of Wedge-tailed Shearwaters Puffinus pacificus) on Heron Island, November, 1985. Еmu 89: 135-139.

Hill, G.J.E., Dyer, P. \& Barnes, A. 1995: The Wedge-tailed Shearwater (Puffinus pacificus) burrows on Heron Island 1985-1990. The Queensland Naturalist 33: 66-70.

Hill, G.J.E., Dyer, P.K., Carter, J.L. \& Barnes, T. 1996: Nesting acrivity, breeding success and colony size for the Wedgetailed Shearwater (Puffinus pacificus) on Heron Island. Australian Journal of Ecology 21: 316-323.

Hill, G. \& Rosier, J. 1989: Wedge-tailed Shearwaters, Whice Capped Noddies and tourist development on Heron Island, Great Barrier Reef Marine Park. Journal of Environmental Management 29: 107-114.

Hill, G., Rosier, J. \& Dyer, P. 1995: Tourism development and environmental limitations at Heron Island, Great Barrier Reef: a response. Journal of Environmental Management 45: 91-99.

Hulsman, K. 1983: Survey of seabird colonies in the Capricornia Section of the Great Barrier Reef Marine Park. II: Population parameters and some management options. Report to the GBRMPA: $104 \mathrm{pp}$.

Hunnam, P. 1983: Heron Island Management Plan. Queensland National Parks and Wildlife Service, Gladstone: $40 \mathrm{pp}$ +2 maps.

Kozlowski, J. 1985: Threshold approach in environmental planning. Ekistics 311: 146-153.

Kozlowski, J., Rosier, J. \& Hill, G. 1988: Ultimate Environmental Threshold (UET) Method in a marine environment (Great Barrier Reef Marine Park in Australia). Landscape and Urban Planning 15: 327-336.

Neil, D. \& Dyer, P.K. 1992: Habitat preference of nesting Wedge-tailed Shearwaters: the effect of soil strength. Corella 16: 34-37

Nelson, B. 1980: Seabirds. Hamlyn, London: 224 pp.

Queensland National Parks and Wildlife Service (QNPWS) 1980: The Green Island Managemenr Plan. QPWS Brisbane: $60 \mathrm{pp}$.

Queensland Parks and Wildlife Service (QPWS) 2000: Management Plan for Capricornia Cays National Park and Capricornia Cays National Park (Scientific). Queensland Parks and Wildlife Service, Rockhampton: 26 pp.

Rosier, J., Hill, G. \& Kozlowski, J. 1986: Environmental limitations: a framework for development on Heron Island. Journal of Environmental Management 23: 59-73.

Segnestam, M. 1975: Land-use planning and bird protection. 12th Bulletin of the International Council for Bird Preservation, London: 233-237.

WBM Oceanics Australia \& Claridge, G. 1997: Guidelines for managing visitation to seabird breeding islands. Great Barrier Reef Marine Park Authority, Townsville: 92 pp.

(accepted 5 August 2008) 